\title{
KJCCM
}

\section{Serum Albumin as a Biomarker of Poor Prognosis in the Pediatric Patients in Intensive Care Unit}

\author{
Young Suh Kim ${ }^{1}$, In Suk Sol ${ }^{1,2}$, Min Jung Kim ${ }^{1,2}$, Soo Yeon Kim ${ }^{1,2}$, Jong Deok Kim ${ }^{1,2}$, \\ Yoon Hee Kim ${ }^{1,3}$, Kyung Won Kim ${ }^{1,2}$, Myung Hyun Sohn ${ }^{1,2}$, and Kyu-Earn Kim ${ }^{1,4}$ \\ ${ }^{1}$ Department of Pediatrics, Yonsei University College of Medicine, Seoul; ${ }^{2}$ Department of Pediatrics, Severance Hospital, Seoul; \\ ${ }^{3}$ Department of Pediatrics, Gangnam Severance Hospital, Seoul; "Sowha Children's Hospital, Seoul, Korea
}

Background: Serum albumin as an indicator of the disease severity and mortality is suggested in adult patients, but its role in pediatric patients has not been established. The objectives of this study are to investigate the albumin level as a biomarker of poor prognosis and to compare it with other mortality predictive indices in children in intensive care unit (ICU).

Methods: Medical records of 431 children admitted to the ICU at Severance Hospital from January 1, 2012 to December 31, 2015 were retrospectively analyzed. Children who expired within 24 hours after ICU admission, children with hepatic or renal failure, and those who received albumin replacement before ICU admission were excluded.

Results: The children with hypoalbuminemia had higher 28 -day mortality rate ( $24.60 \%$ vs. $9.28 \%, \mathrm{P}<0.001)$, Pediatric Index of Mortality (PIM) 3 score (9.23 vs. 8.36, P < 0.001), Pediatric Risk of Mortality (PRISM) III score (7.0 vs. 5.0, P $<0.001$ ), incidence of septic shock (12\% vs. $3 \%, P<0.001)$, C-reactive protein $(33.0 \mathrm{mg} / \mathrm{L}$ vs. $5.8 \mathrm{mg} / \mathrm{L}, \mathrm{P}<0.001)$, delta neutrophil index $(2.0 \%$ vs. $0.6 \%, \mathrm{P}<0.001)$, lactate level $(1.6 \mathrm{mmol} / \mathrm{L}$ vs. $1.2 \mathrm{mmol} / \mathrm{L}, \mathrm{P}<0.001)$ and lower platelet level $(206,000 / \mu \mathrm{l} v \mathrm{vs} 341,000 / \mu \mathrm{l}, \mathrm{P}<0.001)$ compared to the children with normal albumin level. PIM $3(r=0.219, \mathrm{P}<0.001)$ and PRISM III $(r=0.375, \mathrm{P}<0.001)$ were negatively correlated with serum albumin level, respectively.

Conclusions: Our results highlight that hypoalbuminemia can be a biomarker of poor prognosis including mortality in the children in ICU.

Key Words: albumins; intensive care units; mortality; pediatrics.

\section{Introduction}

Predicting the prognosis of patients in intensive care unit (ICU) is important for evaluating the quality of ICU, and making decisions regarding further management [1]. The accurate methods of predicting outcomes of patients have been needed, therefore many scoring systems for predicting prognosis including mortality of patients have been proposed. However, predicting the prognosis of critically ill patients whose condition fluctuates every other moments is challenging. Recently developed assessments based on physiologic variables have limitations due to requiring many variables which are not collected for all patients admitted to ICU [1]. Therefore, it is necessary to identify noninvasive, easy means to predict the prognosis of the patients in ICU, especially for pediatric patients.

\footnotetext{
Received on August 2, 2016 Revised on October 17, 2016 Accepted on November 25, 2016

Correspondence to: Yoon Hee Kim, Department of Pediatrics, Gangnam Severance Hospital, Yonsei University College of Medicine, 211 Eonju-ro, Gangnam-gu, Seoul 06273, Korea

Tel: +82-2-2019-3356, Fax: +82-2-2019-4881, E-mail: yhkim@yuhs.ac

*No potential conflict of interest relevant to this article was reported.
}

cc This is an Open Access article distributed under the terms of the Creative Commons Attribution Non-Commercial License (http://creativecommons.org/ licenses/by-nc/4.0/) which permits unrestricted non-commercial use, distribution, and reproduction in any medium, provided the original work is properly cited. Copyright (c) 2017 The Korean Society of Critical Care Medicine 
The critical condition of patients admitted to the ICU is vulnerable to oxidative stresses caused by reactive oxygen species which result in injuries to cells and tissues and activating extracellular antioxidant defense network consecutively $[2,3]$. There are many antioxidants in extracellular fluids including albumin, which is known as one of the most potent antioxidants [4,5].

Therefore, serum albumin as an indicator of the disease severity and the mortality is suggested and studied in adult patients $[6,7]$ and it has been found that the decrease in serum albumin concentration significantly raises the mortality [8]. Hypoalbuminemia (serum albumin $<3.5 \mathrm{~g} / \mathrm{dl}$ ) is frequently observed in patients admitted to the pediatric intensive care unit (PICU) [2], but its role in pediatric patients has not been established.

In this study, we evaluated the value of serum albumin level at PICU admission as a biomarker of poor prognosis including mortality in critically ill children regardless of underlying etiology and compared serum albumin level with other mortality predictive indices which are universally used in many PICU settings.

\section{Materials and Methods}

\section{1) Study population}

We enrolled 431 pediatric patients admitted to the ICU in Severance Hospital with the exception of cardiology and surgical unit where patients who need cardiologic surgeries admit separately between January 1, 2012 and December 31, 2015. Patients were over 1 month and under 18 years of age. Patients who expired within 24 hours after ICU admission, had hepatic or renal failure, or received albumin replacement before ICU admission were excluded. We defined infection by the presence of a pathogen-proven infection (positive culture, tissue stain, or polymerase chain reaction test) or a clinical syndrome associated with a high probability of infection, such as positive findings on clinical examination, imaging, or laboratory tests (e.g., white blood cells in a normally sterile body fluid, perforated viscus, chest radiograph consistent with pneumonia, petechial or purpuric rash, or purpura fulminans) [9]. This study was approved by the Institutional Review Board of Severance Hospital (protocol No. 4-2013-0207). The informed consent was waived.

\section{2) Data collection}

All data were collected and analyzed retrospectively. Initial blood sample results which obtained at the time of ICU admission were analyzed. Hypoalbuminemia was defined by serum albumin concentration $<3.5 \mathrm{~g} / \mathrm{dl}$. Age, sex, nutritional status, mortality, length of ICU stay, reason for admission, sepsis, septic shock, requirement for respiration support in the first 1 hour of ICU, and requirement for mechanical ventilation within 24 hours of ICU admission were collected.

\section{3) Statistical analysis}

Baseline characteristics of patients were compared using independent two sample t-test and Mann-Whitney Utest, as appropriate. Groups were compared by the chisquare test for categorical variables.

Univariable and multivariable logistic regression model were used to identify independent predictors of mortality and to examine the relation between serum albumin and mortality. The correlation between serum albumin and other mortality predictive indices was assessed using Spearman's method. Survival curves were determined using Kaplan-Meier method. Statistical analyses were performed with IBM SPSS version 23.0 (IBM Corp., Armonk, NY, USA).

The predictive values of serum albumin, Pediatric Index of Mortality (PIM) 3 score, and Pediatric Risk of Mortality (PRISM) III score were compared by calculating the area under the receiver operating characteristic curve (AUC). Receiver operating characteristic curve for discrimination and comparisons of AUCs between other mortality predictive indices and albumin incorporated models (PIM 3 with albumin, and PRISM III with albumin) were used by SAS version 9.3 (SAS Institute, Cary, NC, USA).

Net reclassification improvement (NRI) and integrated 
discrimination improvement (IDI) were performed to assess improvement in mortality prediction after incorporating albumin to PIM 3, PRISM III by using R software version 3.0.1 (R Foundation for Statistical Computing, Vienna, Austria). A P $<0.05$ was considered statistically significant.

\section{Results}

\section{1) Patients' characteristics}

A total of 431 pediatric patients had diverse underlying diseases and reasons for ICU admission (Table 1). The most common underlying disease was neurologic disease (248 patients, 58\%), and others were hemato-oncologic disease (78 patients, $18 \%$ ), pulmonary disease (23 patients, $5 \%$ ), gastro-intestinal disease (15 patients, $3 \%$ ), cardiologic disease (11 patients, 3\%), endocrinologic

Table 1. Underlying disease and main reason for ICU admission of pediatric patients

\begin{tabular}{lc}
\hline Variable & No. $(\%)(\mathrm{n}=431)$ \\
\hline Underlying disease & $248(57.54)$ \\
Neurologic disease & $78(18.10)$ \\
Hemato-oncologic disease & $23(5.34)$ \\
Pulmonary disease & $15(3.48)$ \\
Gastro-intestinal disease & $11(2.55)$ \\
Cardiologic disease & $6(1.39)$ \\
Endocrinologic disease & $6(1.39)$ \\
Nephrologic disease & $1(0.23)$ \\
Metabolic disease & $43(10.00)$ \\
No underlying disease & \\
Main reason for ICU admission & $268(62.18)$ \\
Airway-lung problem & $64(14.85)$ \\
Neurologic problem & $37(8.58)$ \\
Postoperation and procedure care & $15(3.48)$ \\
Hemato-oncologic emergency & $14(3.25)$ \\
Nephrologic problem & $9(2.09)$ \\
Gastrointestinal problem & $3(0.70)$ \\
Metabolic disease & $21(4.87)$ \\
Others ${ }^{a}$ & \\
\hline Lintensie & \\
\hline
\end{tabular}

ICU: intensive care unit.

${ }^{a}$ Endocrinologic emergency, close monitoring, cardiovascular disease. disease (six patients, 1\%), nephrologic disease (six patients, $1 \%$ ), and so on. The most common reason for ICU admission is airway-lung problem (268 patients, 62\%) and other reasons were neurologic problem (64 patients, $15 \%)$, postoperation or procedure care (37 patients, $9 \%$ ), hemato-oncologic problem (15 patients, 3\%), nephrologic problem (14 patients, $3 \%$ ), gastrointestinal problem (nine patients, $2 \%$ ), metabolic diseases (three patients, $1 \%$ ) and others (21 patients, 5\%) sequentially. The pa-

Table 2. Subjects' characteristics

\begin{tabular}{|c|c|}
\hline Variable & Value $(n=431)$ \\
\hline Age (yr) & $3.1(1.1-7.9)$ \\
\hline Male sex & $261(60.56)$ \\
\hline \multicolumn{2}{|l|}{ Nutritional state } \\
\hline Well nourished & $275(63.81)$ \\
\hline Malnourished (weight for age <3\%) & $149(34.57)$ \\
\hline Obese (weight for age $\geq 97 \%$ ) & $7(1.62)$ \\
\hline $\begin{array}{l}\text { Requirement for respiration support within } 1 \\
\text { hour ICU admission }\end{array}$ & $384(89.10)$ \\
\hline $\begin{array}{l}\text { Requirement for mechanical ventilation within } \\
24 \text { hours ICU admission }\end{array}$ & $334(77.49)$ \\
\hline \multicolumn{2}{|l|}{ Laboratory variable } \\
\hline White blood cell (/ML) & $10,930(6,240-17,480)$ \\
\hline Absolute neutrophil count $(/ \mu \mathrm{L})$ & $7,680(3,830-13,253)$ \\
\hline Delta neutrophil index (\%) & $1.5(0.0-5.2)$ \\
\hline Hemoglobin (g/dl) & $10.7(9.2-11.9)$ \\
\hline Platelets $\left(10^{3} / \mu \mathrm{l}\right)$ & $271(151-398)$ \\
\hline Erythrocyte sedimentation rate (mm/h) & $21.0(6.0-57.0)$ \\
\hline C-reactive protein (mg/L) & $13.6(2.6-57.9)$ \\
\hline Lactate (mmol/L) & $1.6(0.9-3.1)$ \\
\hline Serum albumin (g/dl) & $3.4(2.9-3.7)$ \\
\hline Hypoalbuminemia (<3.5 g/dl) & 237 (54.99) \\
\hline Length of ICU stay (d) & $9.0(4.0-18.0)$ \\
\hline \multicolumn{2}{|l|}{ ICU scoring system } \\
\hline PIM 3 & $8.46(4.30-22.63)$ \\
\hline PRISM III & $5.5(2.0-12.0)$ \\
\hline Mortality & $84(19.49)$ \\
\hline 28-Day mortality & $76(17.63)$ \\
\hline Sepsis & $82(19.02)$ \\
\hline Septic shock & $33(7.65)$ \\
\hline
\end{tabular}

Values are presented as median (interquartile range) or number (\%). ICU: intensive care unit; PIM: Pediatric Index of Mortality; PRISM: Pediatric Risk of Mortality. 
tients' baseline characteristics are presented in Table 2 . The median age of patients was 3.1 years, and the number of male patients was $261(60.6 \%)$. The incidence of hypoalbuminemia was $55.0 \%(237 / 431)$.

\section{2) Clinical characteristics by serum albumin level}

Patients were divided into the normoalbuminemia (n $=194)$ and the hypoalbuminemia $(n=237)$ group on the basis of serum albumin level (Table 3 ). No statistically

Table 3. Characteristics in normoalbuminemia and hypoalbuminemia group

\begin{tabular}{|c|c|c|c|}
\hline Variable & Albumin $<3.5 \mathrm{~g} / \mathrm{dl}(\mathrm{n}=237)$ & Albumin $\geq 3.5 \mathrm{~g} / \mathrm{dl}(\mathrm{n}=194)$ & P-value \\
\hline \multicolumn{4}{|l|}{ Clinical characteristic } \\
\hline Age (yr) & $4.0(1.6-8.8)$ & $2.0(0.9-6.7)$ & NS \\
\hline Male sex & $141(59.49)$ & $120(61.86)$ & NS \\
\hline Nutritional state & & & NS \\
\hline Well nourished & $151(63.71)$ & $124(63.92)$ & \\
\hline Malnourished & $83(35.02)$ & $66(34.02)$ & \\
\hline Obese (weight for age $\geq 97 \%$ ) & $3(1.27)$ & $4(2.06)$ & \\
\hline \multicolumn{4}{|l|}{ Main reason for ICU admission } \\
\hline Airway-lung problem & $151(63.71)$ & $117(60.31)$ & NS \\
\hline Neurologic problem & $24(10.13)$ & $40(20.62)$ & NS \\
\hline Postoperation and procedure care & $22(9.28)$ & $15(7.73)$ & NS \\
\hline Hemato-oncologic emergency & $10(4.22)$ & $5(2.58)$ & NS \\
\hline Nephrologic problem & $9(3.80)$ & $5(2.58)$ & NS \\
\hline Gastrointestinal problem & $8(3.38)$ & $1(0.52)$ & NS \\
\hline Metabolic disease & $1(0.42)$ & $2(1.03)$ & NS \\
\hline Others $^{\mathrm{a}}$ & $12(5.06)$ & $9(4.64)$ & NS \\
\hline \multicolumn{4}{|l|}{ Laboratory variable } \\
\hline 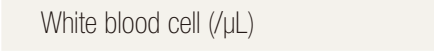 & $9,190(5,580-15,960)$ & $12,640(7,685-18,603)$ & NS \\
\hline Absolute neutrophil count (/ $/ \mathrm{L})$ & $6,700(3,303-11,763)$ & 8,922 (4,803-14,223) & NS \\
\hline Delta neutrophil index (\%) & $2.0(0.0-7.1)$ & $0.6(0.0-3.6)$ & $<0.001$ \\
\hline Hemoglobin (g/dl) & $10.2(8.8-11.4)$ & $11.0(9.8-12.1)$ & $<0.001$ \\
\hline Platelets $\left(10^{3} / \mu l\right)$ & 206 (96-335) & $341(232-475)$ & $<0.001$ \\
\hline Erythrocyte sedimentation rate $(\mathrm{mm} / \mathrm{h})$ & $23.0(7.0-64.5)$ & $19.5(4.75-48.0)$ & NS \\
\hline C-reactive protein (mg/L) & $33.0(8.5-97.5)$ & $5.8(0.9-24.2)$ & $<0.001$ \\
\hline Lactate (mmo/L) & $1.6(0.9-3.1)$ & $1.2(0.7-1.9)$ & $<0.001$ \\
\hline Length of ICU stay (d) & $10.0(4.0-19.0)$ & $7.0(4.0-17.0)$ & NS \\
\hline \multicolumn{4}{|l|}{ ICU scoring system } \\
\hline PIM 3 & $9.23(4.52-29.48)$ & 8.36 (3.80-18.80) & $<0.001$ \\
\hline PRISM III & $7.0(3.0-13.0)$ & $5.0(0-10.0)$ & $<0.001$ \\
\hline Mortality & $64(27.00)$ & $20(10.31)$ & $<0.001$ \\
\hline 28-Day mortality & $59(24.60)$ & $18(9.28)$ & $<0.001$ \\
\hline Sepsis & $53(22.36)$ & $29(14.95)$ & NS \\
\hline Septic shock & $28(11.81)$ & $5(2.58)$ & $<0.001$ \\
\hline
\end{tabular}

Values are presented as median (interquartile range) or number (\%).

NS: non-specific; ICU: intensive care unit; PIM: Pediatric Index of Mortality; PRISM: Pediatric Risk of Mortality.

${ }^{a}$ Endocrinologic emergency, close monitoring, cardiovascular disease. 
significant difference was observed in the age, sex, the nutritional status, the length of ICU stay, and the main reason for ICU admission between two groups.

The patients with hypoalbuminemia had higher delta neutrophil index $(2.0 \%$ vs. $0.6 \%, \mathrm{P}<0.001)$, C-reactive protein $(33.0 \mathrm{mg} / \mathrm{L}$ vs. $5.8 \mathrm{mg} / \mathrm{L}, \mathrm{P}<0.001)$, lactate level $(1.6 \mathrm{mmol} / \mathrm{L}$ vs. $1.2 \mathrm{mmol} / \mathrm{L}, \mathrm{P}<0.001)$, PIM 3 (9.23 vs. $8.36, \mathrm{P}<0.001)$, PRISM III (7.0 vs. 5.0, $\mathrm{P}<0.001)$, 28 day mortality rate $(24.60 \%$ vs. $9.28 \%, \mathrm{P}<0.001)$, incidence of septic shock $(11.8 \%$ vs. $2.6 \%, \mathrm{P}<0.001)$, and lower hemoglobin level $(10.2 \mathrm{~g} / \mathrm{dl}$ vs. $11.0 \mathrm{~g} / \mathrm{dl}, \mathrm{P}<0.001)$ and platelet level $(206,000 / \mu 1$ vs. $341,000 / \mu 1, \mathrm{P}<0.001)$ compared to the normoalbuminemia group (Table 3).

\section{3) Clinical characteristics in infection and non-infection} group by serum albumin level

Patients were divided into infection group $(\mathrm{n}=299)$ and non-infection group $(\mathrm{n}=132)$ as we defined in the Materials and Methods. No statistically significant difference was observed in the age, sex, the nutritional status, and the length of ICU stay in both infection and non-infection group (Supplementary Tables 1 and 2). The patients with hypoalbuminemia had higher delta neutrophil index, Creactive protein, lactate level, PIM 3, PRISM III, 28-day mortality rate, incidence of septic shock, and lower hemoglobin level and platelet level compared to the normoalbuminemia patients in both infection and non-infection group (Supplementary Tables 1 and 2). This is consistent with the result of comparison of clinical characteristics in the total group by serum albumin level (Table 3).

\section{4) Clinical characteristics in infant and the other group by serum albumin level}

Patients were divided by the age, infant group $(n=96)$ and the other group (age, $\geq 1$ year; $n=335$ ). No statistically significant difference was observed in the age, sex, the nutritional status, and the length of ICU stay in both age group (Supplementary Tables 3 and 4). The patients with hypoalbuminemia had higher delta neutrophil index, Creactive protein, lactate level, PIM 3, PRISM III, 28-day mortality rate, incidence of septic shock, and lower platelet level compared to the normoalbuminemia patients in both age groups as others (Supplementary Tables 3 and 4). Hemoglobin level was statistically significant in patients who were above 1 year old, but not for infant group.

\section{5) Serial serum albumin levels for the first 4 days in ICU}

We compared serial serum albumin levels for the first 4 days in ICU between survivors and non-survivors in hypoalbuminemia and normoalbuminemia group separately (Figure 1). Serum albumin level in survivors remained higher than non-survivors in both groups. Serum albumin level of non-survivors was below $3.5 \mathrm{~g} / \mathrm{dl}$ in the second, third, and fourth day in ICU in both groups.
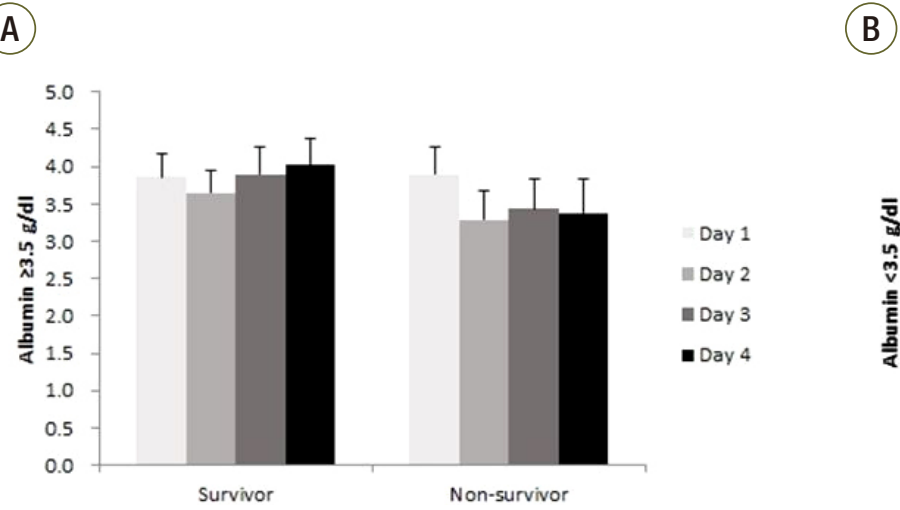

B)

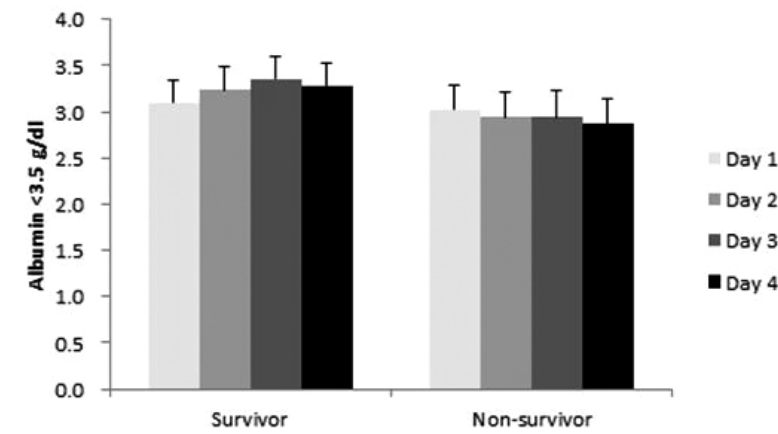

Figure 1. Albumin level in the first 4 days in intensive care unit in (A) normoalbuminemia group and $(B)$ in hypoalbuminemia group. The box and plots represent mean and standard deviation. 
Table 4. Univariable logistic regression for independent factor in mortality prediction

\begin{tabular}{lccc}
\hline Variable & Odds ratio & 95\% Confidence interval & P-value \\
\hline Age & 1.058 & $1.004-1.114$ & 0.034 \\
Sex & 0.932 & $0.560-1.551$ & 0.787 \\
Pediatric Index of Mortality 3 & 1.031 & $1.023-1.038$ & $<0.001$ \\
Pediatric Risk of Mortality III & 1.185 & $1.139-1.232$ & $<0.001$ \\
Albumin & 0.34 & $0.233-0.496$ & $<0.001$ \\
C-reactive protein & 1.008 & $1.005-1.010$ & $<0.001$ \\
Delta neutrophil index & 1.079 & $1.054-1.105$ & $<0.001$ \\
Lactate & 1.245 & $1.167-1.328$ & $<0.001$ \\
Platelet & 0.995 & $0.993-0.997$ & $<0.001$ \\
\hline
\end{tabular}

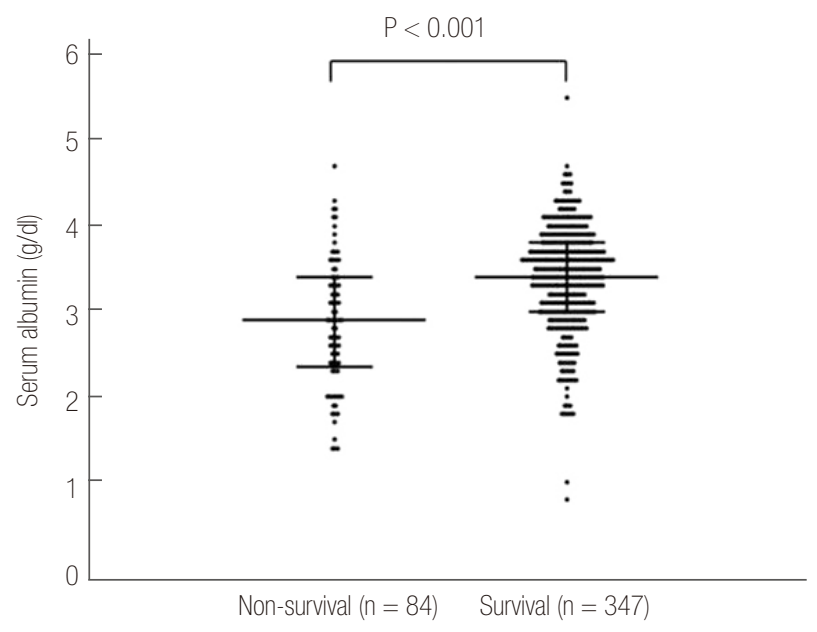

Figure 2. Albumin level between non-survival and survival group. Serum albumin level in the survival group was higher than the non-survival group ( $3.4 \mathrm{~g} / \mathrm{dl}$ [interquartile range, 3 to 3.8 $\mathrm{g} / \mathrm{dl}$ ] vs. $2.9 \mathrm{~g} / \mathrm{dl}$ [interquartile range, 2.3 to $3.4 \mathrm{~g} / \mathrm{dl}$ ], $\mathrm{P}<0.001$ ). The error bar represents the median and interquartile range for each group.

\section{6) Albumin as a predictor of mortality in PICU patients}

Serum albumin level in the survival group is higher than that in the non-survival group $(3.4 \mathrm{~g} / \mathrm{dl}$ [interquartile range, 3 to $3.8 \mathrm{~g} / \mathrm{dl}$ ] vs. $2.9 \mathrm{~g} / \mathrm{dl}$ [interquartile range, 2.3 to $3.4 \mathrm{~g} / \mathrm{dl}], \mathrm{P}<0.001$ ) (Figure 2). Figure 3 shows survival curves according to albumin level and it shows that the normoalbuminemia group has higher survival probability than the hypoalbuminemia group. In the univariable analyses, nine variables including albumin were correlated with the mortality $(\mathrm{P}<0.001)$ (Table 4$)$.

We also considered the relationship between serum albumin at admission and pre-existing mortality prediction

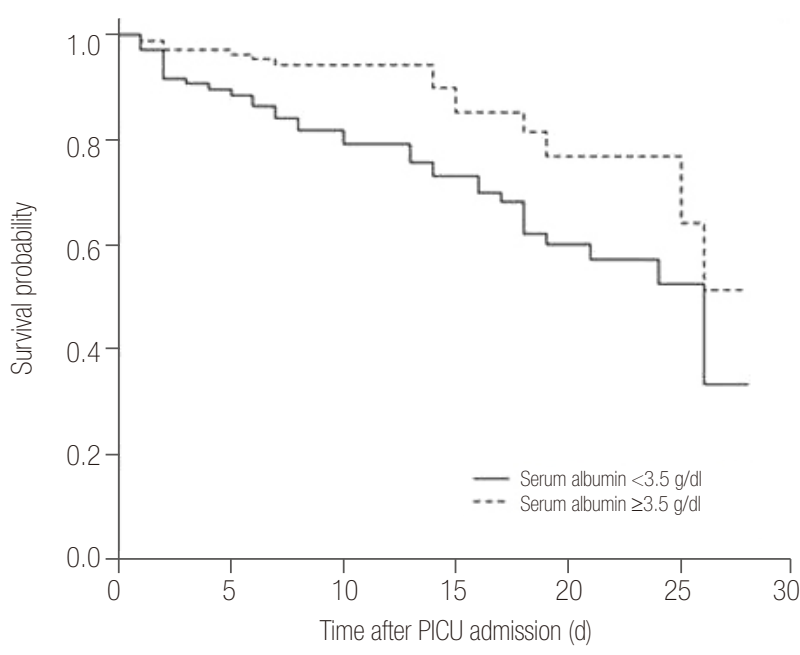

Figure 3. Survival probability according to albumin level. Kaplan-Meier survival estimate for patients according to serum albumin level (albumin $<3.5 \mathrm{~g} / \mathrm{dl}$ vs. albumin $\geq 3.5 \mathrm{~g} / \mathrm{dl}$ ). This survival curve showed that the hypoalbuminemia group had lower survival probability than the normoalbuminemia group. PICU: pediatric intensive care unit.

models used in ICU. Even though the correlation coefficients were low, each model was significantly correlated with serum albumin (Supplementary Table 5). The AUC was 0.702 for serum albumin, 0.802 for PIM 3, and 0.850 for PRISM III score (Figure 4, Supplementary Table 5).

There was no improvement of predicting mortality in the corporation of serum albumin to pre-existing mortality prediction models; however, incorporating albumin to pre-existing mortality prediction models showed a tendency to be more predictive of mortality than PIM 3, PRISM III alone (Supplementary Table 6). The PIM 3 with serum albumin provided an NRI of $21.0 \%(\mathrm{P}=$ 


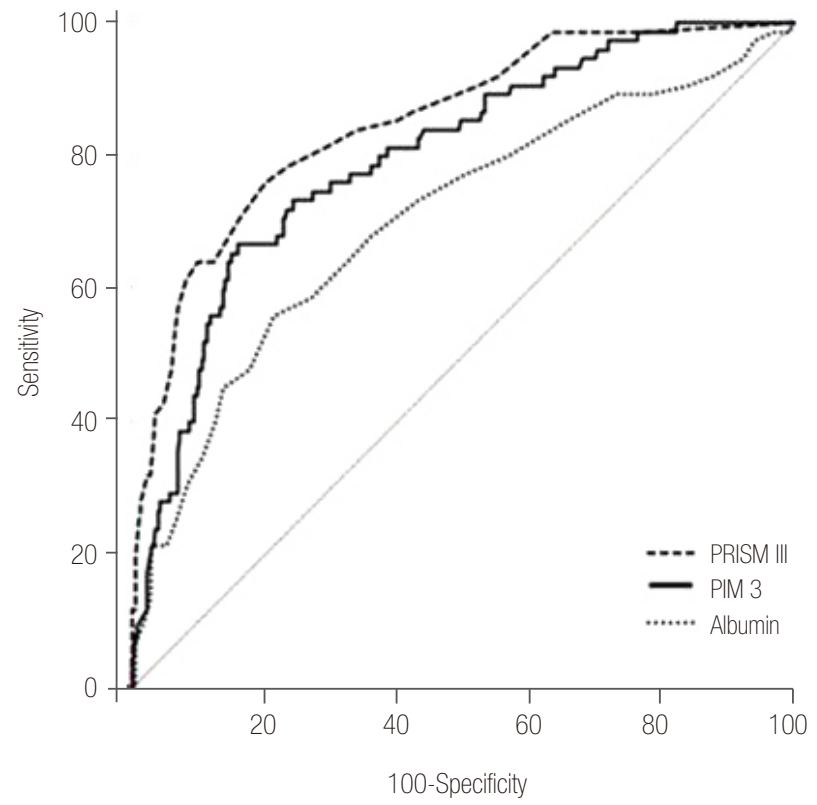

Figure 4. Receiver operating characteristic curves for mortality between albumin and intensive care unit mortality scoring systems. Area under the receiver operating characteristic curve: PRISM III, 0.850 (95\% Cl, 0.801 to 0.899); PIM 3, 0.802 (95\% CI, 0.747 to 0.858$)$; albumin, $0.702(95 \% \mathrm{Cl}, 0.633$ to 0.772$)$. PRISM: Pediatric Risk of Mortality; PIM: Pediatric Index of Mortality; Cl: confidence interval.

$0.136)$ and IDI of $4.3 \%(P=0.158)$, and the PRISM III with serum albumin yielded an NRI of $24.5 \%(\mathrm{P}=0.388)$ and IDI of $2.1 \%(\mathrm{P}=0.416)$ (Supplementary Table 7).

\section{Discussion}

We showed that serum albumin concentration at ICU admission was higher in survivors compared with nonsurvivors in children. Patients with hypoalbuminemia at ICU admission had higher mortality rate. In addition, serum albumin concentration was negatively correlated with pre-existing mortality prediction models including PIM 3 and PRISM III.

The prevalence of hypoalbuminemia in critically ill children is about $33 \%-57 \%$ from previous studies [1012]. Hypoalbuminemia has long been a predictor of poor outcome, such as mortality, morbidity, and prolonged ICU and hospital stay [5]. There are many studies that low serum albumin concentration reflects disease severity and prognosis in critically ill adult patients [13-16]. Regarding pediatric patients, studies on this issue were limited to only some specific circumstances, such as cardiac surgery children, pediatric renal transplant recipients, showing that hypoalbuminemia is a risk factor for cardiac surgery and graft failure $[17,18]$. Serum albumin concentration as a predictor of clinical outcomes of critically ill children in general circumstances is so far inconclusive $[10,11]$.

Albumin plays important role as an osmotic pressure determinant balancing between intravascular and interstitial space, a non-specific carrier protein, and an antioxidant by scavenging of oxygen free radicals to protect against oxidant injuries [19,20]. The important determinants of serum albumin concentration in critically ill patients are synthetic rate and leakage of albumin to interstitial space from intravascular space $[19,21]$. As the clinical course of critically ill patients progresses, the distribution of albumin from intravascular to interstitial spaces occurs resulting from increases of capillary leakage by the response of systemic inflammation [20]. Since the leakage of albumin into the extravascular spaces is related to the degree of systemic inflammation [22], the development of hypoalbuminemia is liable to be seen in patients with poor clinical status. Owing to potency of albumin as an antioxidant agent, in addition to this kinetic and dynamic alteration of albumin in critically ill patients, hypoalbuminemia is associated with poor clinical outcomes such as mortality, morbidity and prolonged hospital stay in critically ill patients $[5,23]$.

Mortality is the worst outcome of clinical management in ICU setting. Early recognition of probability of mortality in critically ill patients can help to make prompt and precise decision to give the best treatment to patients by risk stratification. Therefore, predicting mortality risk is a major concern of ICU care. Several predictive indices have been suggested to predict the risk of death in critically ill children of ICU, but some predictive indices are too complicated demanding too much information to calculate the mortality risk. As a result, there has been 
an increasing need to establish a clinical value to use in children in ICU easily. Several biomarkers such as delta neutrophil index, C-reactive protein, and thrombocytopenia have been suggested as predictors of poor prognosis including mortality in children in ICU [24-26].

We designed this study to investigate whether hypoalbuminemia at admission can predict prognosis including mortality in pediatric patients in ICU. Comparing hypoalbuminemia group of patients and normoalbuminemia group of patients, we showed that hypoalbuminemia at admission to ICU was associated with the higher mortality, regardless of the underlying disease. Furthermore, even though there was no statistical significance, incorporation of serum albumin at admission to other predictive indices showed a tendency to be more predictive in this study. This shows that serum albumin concentration, which could be obtained through a simple, sensitive, low cost assay, could help assessing the current status and predicting outcomes of critically ill pediatric patients in ICU.

There are some limitations in the current study. First, this study was limited to the single center using the data collected retrospectively. Since serum albumin level below $2.5 \mathrm{~g} / \mathrm{dl}$ were replaced and above $2.5 \mathrm{~g} / \mathrm{dl}$ were not in this retrospective data, this study was not able to evaluate the effectiveness of albumin replacement. Therefore, further studies might be needed in a multicenter setting using prospective data.

In conclusion, hypoalbuminemia at admission was associated with higher mortality in children in ICU. We suggest that hypoalbuminemia at admission could be used as a biomarker of poor prognosis of children in ICU, regardless of underlying etiology.

\section{ORCID}

Young Suh Kim

http://orcid.org/0000-0002-4429-8676

In Suk Sol http://orcid.org/0000-0003-2470-9682

Min Jung Kim http://orcid.org/0000-0002-5634-9709

Jong Deok Kim
Yoon Hee Kim http://orcid.org/0000-0002-2149-8501

Kyung Won Kim http://orcid.org/0000-0003-4529-6135

Myung Hyun Sohn http://orcid.org/0000-0002-2478-487X

Kyu-Earn Kim http://orcid.org/0000-0002-5730-3331

\section{Supplementary Materials}

The online-only Supplement data are available with this article online: https://doi.org/10.4266/kjccm.2017.00437.

\section{References}

1. Straney L, Clements A, Parslow RC, Pearson G, Shann F, Alexander J, et al. Paediatric index of mortality 3: an updated model for predicting mortality in pediatric intensive care. Pediatr Crit Care Med 2013;14:673-81.

2. Sitar ME, Aydin S, Cakatay U. Human serum albumin and its relation with oxidative stress. Clin Lab 2013;59:945-52.

3. Abiles J, de la Cruz AP, Castano J, Rodriguez-Elvira M, Aguayo E, Moreno-Torres R, et al. Oxidative stress is increased in critically ill patients according to antioxidant vitamins intake, independent of severity: a cohort study. Crit Care 2006;10:R146.

4. Oettl K, Stauber RE. Physiological and pathological changes in the redox state of human serum albumin critically influence its binding properties. Br J Pharmacol 2007; 151:580-90.

5. Vincent JL, Dubois MJ, Navickis RJ, Wilkes MM. Hypoalbuminemia in acute illness: is there a rationale for intervention? A meta-analysis of cohort studies and controlled trials. Ann Surg 2003;237:319-34.

6. Barchel D, Almoznino-Sarafian D, Shteinshnaider M, Tzur I, Cohen N, Gorelik O. Clinical characteristics and prognostic significance of serum albumin changes in an internal medicine ward. Eur J Intern Med 2013;24:772-8.

7. Jellinge ME, Henriksen DP, Hallas P, Brabrand M. 
Hypoalbuminemia is a strong predictor of 30-day allcause mortality in acutely admitted medical patients: a prospective, observational, cohort study. PLoS One 2014;9:e105983.

8. Nagumo K, Tanaka M, Chuang VT, Setoyama H, Watanabe H, Yamada N, et al. Cys34-cysteinylated human serum albumin is a sensitive plasma marker in oxidative stress-related chronic diseases. PLoS One 2014;9:e85216.

9. Goldstein B, Giroir B, Randolph A; International Consensus Conference on Pediatric Sepsis. International pediatric sepsis consensus conference: definitions for sepsis and organ dysfunction in pediatrics. Pediatr Crit Care Med 2005;6:2-8.

10. Durward A, Mayer A, Skellett S, Taylor D, Hanna S, Tibby SM, et al. Hypoalbuminaemia in critically ill children: incidence, prognosis, and influence on the anion gap. Arch Dis Child 2003;88:419-22.

11. Horowitz IN, Tai K. Hypoalbuminemia in critically ill children. Arch Pediatr Adolesc Med 2007;161:1048-52.

12. Tiwari LK, Singhi S, Jayashree M, Baranwal AK, Bansal A. Hypoalbuminemia in critically sick children. Indian J Crit Care Med 2014;18:565-9.

13. Apelgren KN, Rombeau JL, Twomey PL, Miller RA. Comparison of nutritional indices and outcome in critically ill patients. Crit Care Med 1982;10:305-7.

14. Bradley JA, Cunningham KJ, Jackson VJ, Hamilton DN, Ledingham IM. Serum protein levels in critically ill surgical patients. Intensive Care Med 1981;7:291-5.

15. Murray MJ, Marsh HM, Wochos DN, Moxness KE, Offord KP, Callaway CW. Nutritional assessment of intensive-care unit patients. Mayo Clin Proc 1988;63:1106-15.
16. Marik PE. The treatment of hypoalbuminemia in the critically ill patient. Heart Lung 1993;22:166-70.

17. Leite HP, Fisberg M, de Carvalho WB, de Camargo Carvalho AC. Serum albumin and clinical outcome in pediatric cardiac surgery. Nutrition 2005;21:553-8.

18. Tancredi DJ, Butani L. Pretransplant serum albu$\mathrm{min}$ is an independent predictor of graft failure in pediatric renal transplant recipients. J Pediatr 2014;164:602-6.

19. Emerson TE Jr. Unique features of albumin: a brief review. Crit Care Med 1989;17:690-4.

20. Nicholson JP, Wolmarans MR, Park GR. The role of albumin in critical illness. Br J Anaesth 2000;85:599610.

21. Whicher J, Spence C. When is serum albumin worth measuring? Ann Clin Biochem 1987;24(Pt 6):572-80.

22. Fleck A, Raines G, Hawker F, Trotter J, Wallace PI, Ledingham IM, et al. Increased vascular permeability: a major cause of hypoalbuminaemia in disease and injury. Lancet 1986;1:781-4.

23. Goldwasser P, Feldman J. Association of serum albumin and mortality risk. J Clin Epidemiol 1997;50:693-703.

24. Seok Y, Choi JR, Kim J, Kim YK, Lee J, Song J, et al. Delta neutrophil index: a promising diagnostic and prognostic marker for sepsis. Shock 2012;37:242-6.

25. Ho KM, Lee KY, Dobb GJ, Webb SA. C-reactive protein concentration as a predictor of in-hospital mortality after ICU discharge: a prospective cohort study. Intensive Care Med 2008;34:481-7.

26. Agrawal S, Sachdev A, Gupta D, Chugh K. Platelet counts and outcome in the pediatric intensive care unit. Indian J Crit Care Med 2008;12:102-8. 